Supplement of Earth Syst. Dynam., 11, 77-96, 2020

https://doi.org/10.5194/esd-11-77-2020-supplement

(C) Author(s) 2020. This work is distributed under

the Creative Commons Attribution 4.0 License.

(c) (1)
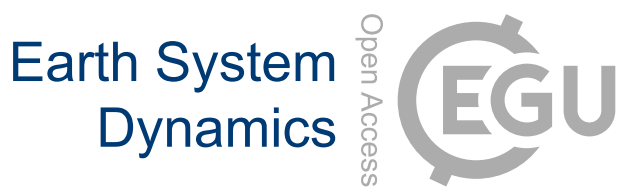

Supplement of

\title{
Synthesis and evaluation of historical meridional heat transport from midlatitudes towards the Arctic
}

Yang Liu et al.

Correspondence to: Yang Liu (y.liu@esciencecenter.nl)

The copyright of individual parts of the supplement might differ from the CC BY 4.0 License. 


\section{Supplementary material}

In summer, the situation becomes more intricate and unclear. The instantaneous regressions of anomalies of multiple fields on AMET anomalies at $60 \mathrm{~N}$ in each atmospheric product in summer are shown in Figure S1. A high pressure center in the central Arctic is linked to an increase in AMET in all products. However, large differences are found in the relations between AMET and T2M and SIC. Consequently, the consistency between surface fields and AMET between chosen products in summer is even worse compared to winter. Given the differences between chosen reanalyses and relatively low statistical significance, it is quite difficult to make inference about the relation between AMET and T2M and SIC in summer.

Similar issues are found in the regressions of the same fields on OMET at $60 \mathrm{~N}$ in each oceanic reanalysis product in summer, which are shown in Figure S2 with OMET leads by 1 month. Regarding the relations between OMET and SLP, a dipole pattern is observed in each oceanic reanalysis dataset, but the patterns are different in ORAS4 and SODA3 compared to those in GLORYS2V3. Different relations between OMET and T2M are found among all the products. In all the chosen oceanic reanalyses data sets, SLP and T2M are weakly correlated with OMET compared to those in winter. Although strong correlations between SIC and OMET are found in each oceanic reanalysis product (Figure S2 g, h and i), the patterns are not consistent among them. Note that the statistical significance in these regressions are very low. 
ERA-Interim

(a)

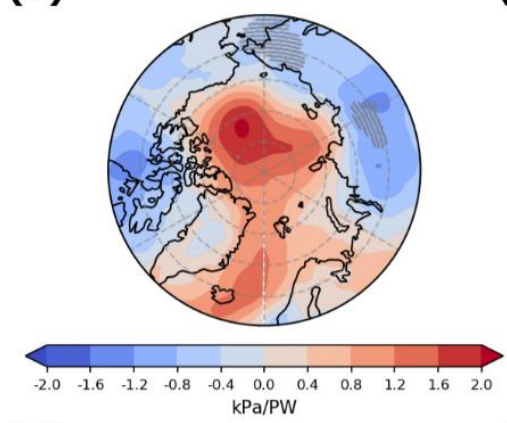

(d)

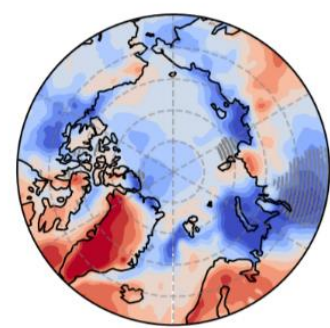

$\begin{array}{lllllllllll}0.0 & -8.0 & -6.0 & -4.0 & -2.0 & 0.0 & 2.0 & 4.0 & 6.0 & 8.0 & 10.0\end{array}$

(g)

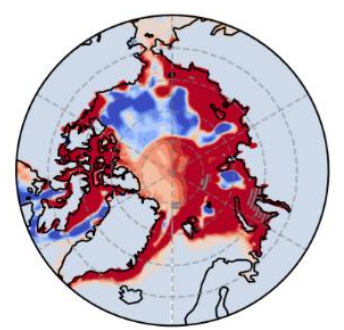

MERRA2

(b)
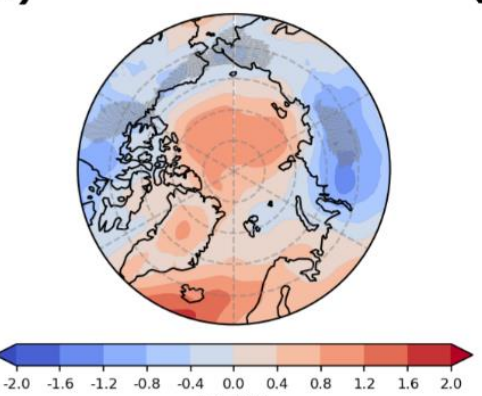

(e)
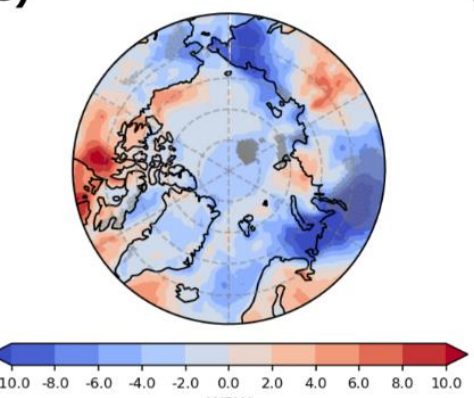

(h)

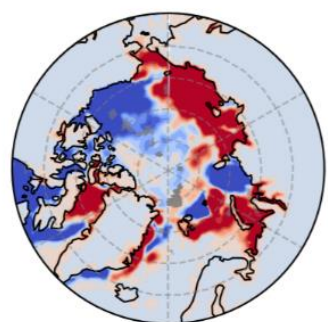

(i)

(f)

(c)

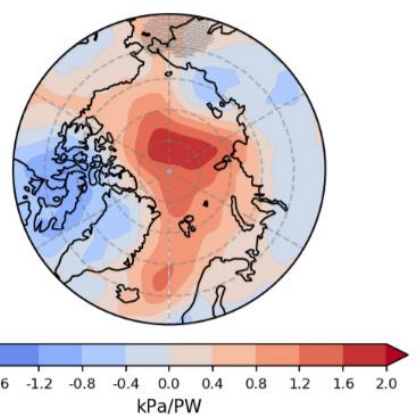

SLP

T2M
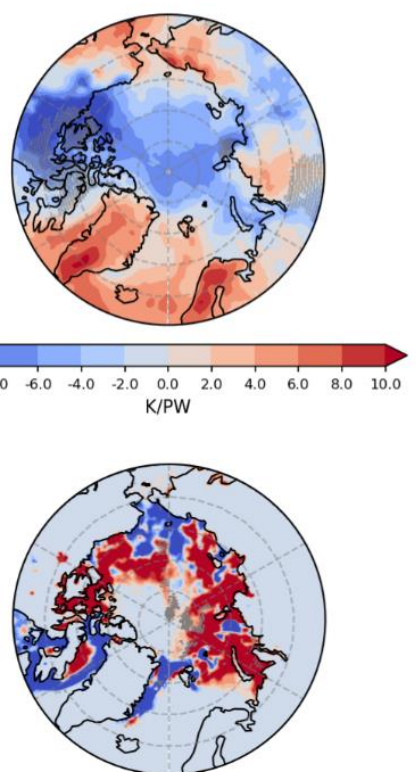

SIC

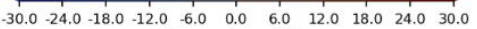
Percentage/PW

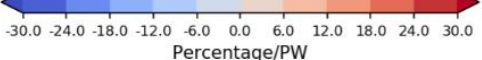

$\begin{array}{lllllllllll}-30.0 & -24.0 & -18.0 & -12.0 & -6.0 & 0.0 & 6.0 & 12.0 & 18.0 & 24.0 & 30.0\end{array}$ Percentage/PW

Figure S1. Regressions of sea level pressure, 2 meter temperature and sea ice concentration anomalies on AMET anomalies at $60 \mathrm{~N}$ in summer (JJA) at interannual time scales with no time lag. The monthly mean fields are used here after taking a running mean of 5 year. Both the 2 meter temperature and sea ice concentration are detrended. From left to right, they are the regressions on AMET of $(a, d, g)$ ERAInterim, (b, e, h) MERRA2 and (c, f, i) JRA55. The stippling indicates a significance level of $95 \%$. 
ORAS4

(a)

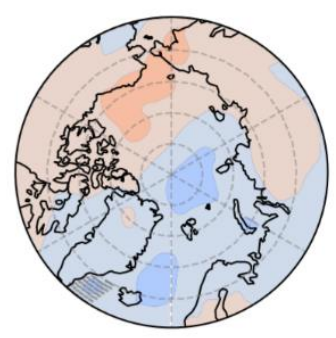

(d)

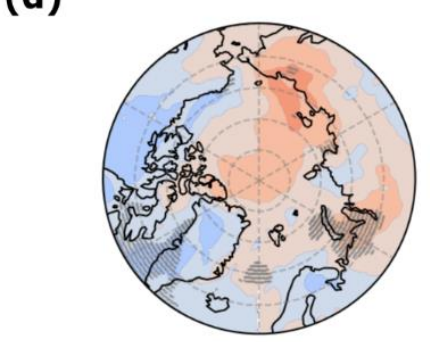

(e)

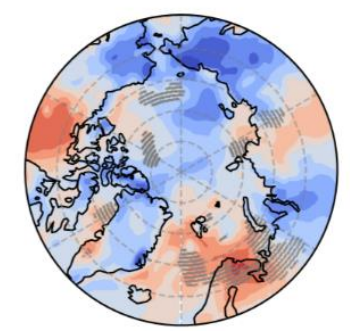

(b)

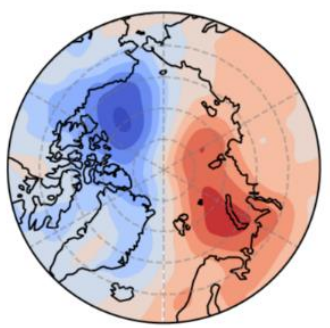

(c)

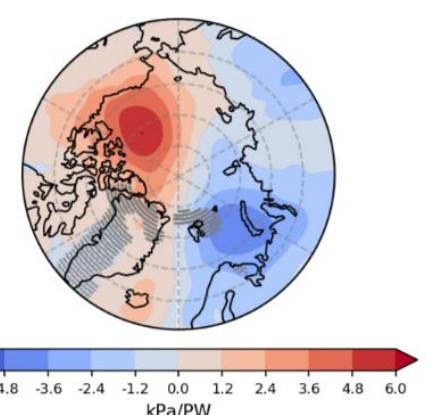

SLP

(f)

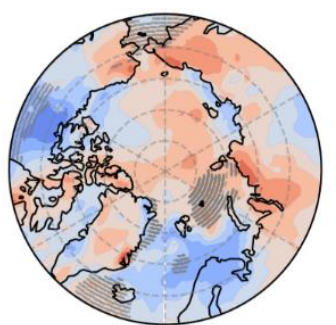

T2M

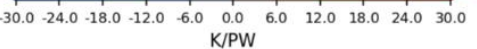

(g)

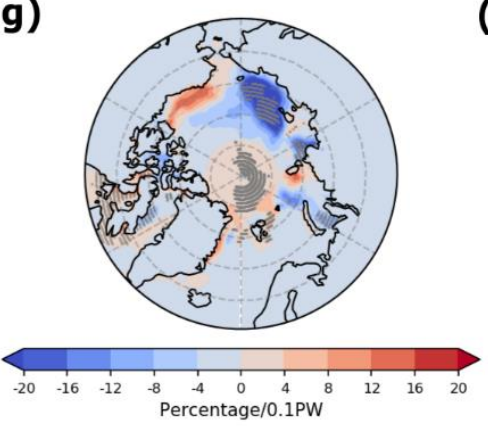

(h)

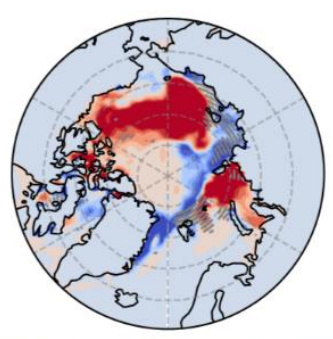

(i)

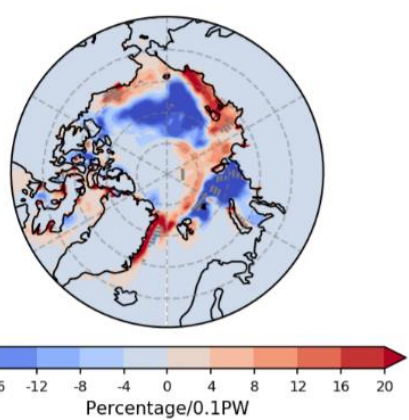

SIC

Figure S2 Regressions of sea level pressure, 2 meter temperature and sea ice concentration anomalies on OMET anomalies at $60 \mathrm{~N}$ in summer (JJA) at interannual time scales. OMET leads the fields by one month. The 2 meter temperature, sea ice concentration and OMET are detrended. From left to right, they are the regression on OMET of $(a, d, g)$ ORAS4, $(b, e, h)$ GLORYS2V3 and $(c, f, i)$ SODA3. The stippling indicates a significance level of $95 \%$. 